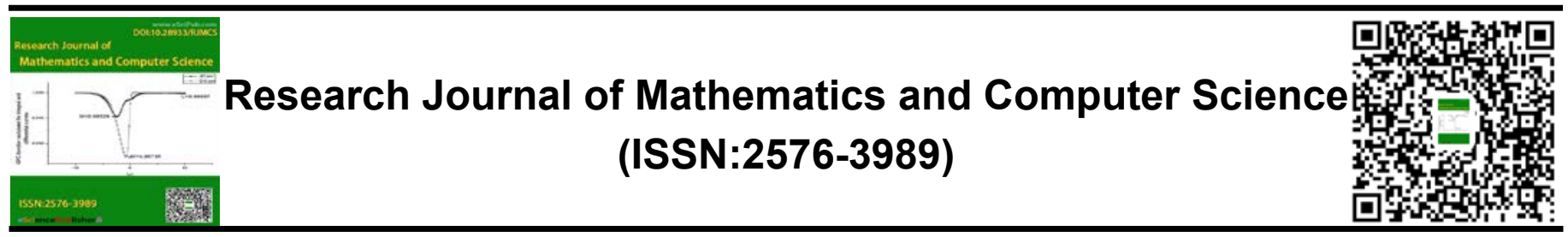

\title{
A Neuro-Fuzzy System For Diagnosis of Soya-Beans Diseases
}

\author{
Rahmon,I.A, Adebola_Akinsanya and Eze, M.O \\ Department of Computer Science, Babcock University,llishan-Remo, Ogun State, Nigeria.
}

\begin{abstract}
Soyabean is an important legume crop, extensively cultivated for ${ }^{*}$ Correspondence to Author: food on which low-income population highly depend because of Rahmon,I.A its proteineous nutrient on daily basis for food.The efforts of farm- Department of Computer Science, ers to specifically identify the specific pests responsible for dam- Babcock University,llishan-Remo, aging of plants segment such as petioles, roots, stem, pod and Ogun State, Nigeria leaves still remain vague and imprecise to many farmers. In this work, a neuro-fuzzy system will be built with MATLAB version 8 with 100 rules on five input parameters as linguistic variables or symptoms into the system to determine the disease type either as fungi or bacteria or virus, and to also determine intensity rate as the output in form of a crisp. The output of the system will produce results for the decision maker to provide solution regarding the treatment of the infected plant for bountiful and quality harvest.

How to cite this article:

Rahmon,I.A, Adebola_Akinsanya and Eze, M.O, A Neuro-Fuzzy System For Diagnosis of SoyaBeans Diseases. Research Journal of Mathematics and Computer Science, $2018 ; 2: 13$

Keywords:Neuro-fuzzy system,crisp,matlab.

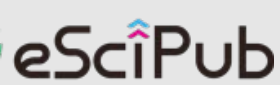

eSciPub LLC, Houston, TX USA.

Website: http://escipub.com/
\end{abstract}




\section{INTRODUCTION}

The technological evolution in computing has been the principal tool in increasing agricultural products. Nevertheless, there are numerous problems and constraints working against the bountiful and quality harvest of soyabean commercial production Dugje et al (2009). ICTs play vital role in facilitating agricultural growth. The scientific and technological developments which include e-agriculture, decision support system for farmers and mobile applications have tremendously delivered relevant services for farmers in tackling all forms of crop diseases. ICTs have promoted new farming techniques and distributed new knowledge through the use of computing technology for facilitating diagnosis and treatment of crop diseases, Swanson and Rajalahti (2010).

Expert system is a branch of artificial intelligence that is highly beneficial to many experts in various fields in providing solution to some uncertain and imprecise tasks. The capacity and efficiency of expert system in imitating human reasoning process and providing relevant advice similar to human expertise has singled it out as one of the artificial intelligence branches widely embraced in many fields today, Yialouris and Sideridis (1996). Neuro-fuzzy is also one of the artificial intelligence $(\mathrm{Al})$ techniques which has always been adopted by some researchers for decades, in developing systems that provided optimal solution to problems that are vague and imprecise in nature. Neuro-fuzzy is an efficient technique that combines the strength of neuralnetwork and fuzzy logic together by utilizing the approximation method of neural-network to compute the parameters of a fuzzy system. The architecture of neuro-fuzzy with various functionalities in layers makes it more suitable to develop a system that will have its final output more optimized.

The choice of neuro-fuzzy technique for this work is justified as a result of need to accept five major symptoms of soyabean disease as input parameters for disease classification and computation of intensity proportion of a particular disease.

\section{STATEMENT OF THE PROBLEM}

Findings have shown that non-availability of improved and modern technologies is the main constraints in agricultural production in Nigeria, Asoegwu (2007).

Few researches in the past have virtually demonstrated the fuzzy-logic based system for diagnosing crop diseases while a few authors only adopted neural-network technique to develop expert system for soyabean. But, hybridization techniques of $\mathrm{Al}$ in which different techniques are combined together to develop more robust expert system is fairly ignored Dybowsky and Gant( 2015).

Due to this research gap, there is a need to apply a hybrid of neural network and fuzzy logic together to form a robust and highly intelligent system for optimal solution.

\section{AIM AND OBJECTIVES}

The aim of this study is to develop an interactive neuro-fuzzy based system for identifying specific disease and determining the degree of damage (intensity level) perpetrated on a soyabean plant. The specific objectives are;

I. Review literature on interactive neurofuzzy based system.

II. Design a neuro-fuzzy based system with five input parameter fields as symptoms on root, leaves, stem, flowers and pod, with two outputs for disease type and intensity level of the disease respectively.

III. Model the dataset extracted from a database for training through the aid of Adaptive Neuro-Fuzzy Inference System (ANFIS).

IV. Implement,test and evaluate the neurofuzzy based system.

\section{SIGNIFICANCE OF THE STUDY}

Indigenous farmers usually diagnose crop diseases in forms of linguistic values that are 
imprecise, and can easily constitute uncertainty and vagueness." The significance of this work isprovision of solution to Soyabean diseases caused by fungi, bacteria and viruses which are responsible for low production of soyabean crop annually" Dugje et al (2009). The significance of this study is that neuro-fuzzy technique is;

I. An efficient technique for all forms of natural diversity that exist in computing the intensity level of soyabean crop disease.

II. A promising platform and interface for farmers to make justifiable conclusion based on the input-parameters and corresponding computed output.

\section{SCOPE OF THE STUDY}

This study is strictly restricted within the scope of using a particular type of neuro-fuzzy known as Adaptive Neuro-Fuzzy Inference System (ANFIS) to develop a system that capture specific input parameters as symptom on leaves, pod, root, flower and stem of soyabean plant and identify disease-type the plant infected with, along with the extent or degree of the infection as output.

\section{LITERATURE REVIEW}

The adoption of expert system in providing upto-date information and diagnosis of crop diseases in agriculture could be dated back to 1980. It is not a new concept because a large number of agricultural institutes and researchers across the globe have been developing different types of expert system for local farmers within their regions and catchment areas. Every expert system requires human expertise to provide knowledge-base that could be encoded in solving related problems in a specified domain, Patterson (2004).

A tremendous advancement of technology in software and hardware industries has provided opportunities for researchers to explore every aspect of artificial intelligence techniques in building relevant systems and devices for indigenous farmers. It should be noted that expert system can be developed in different ways, depending on the theory or technique adopted by developers to enhance its efficiency. In computer science, many researchers have adopted the use of neural network, and fuzzy logic as artificial intelligence techniques in enhancing the effectiveness and efficiency of expert systems for agricultural use. Farming all over the world has embraced all forms of technological advancement in classifying livestock disorders, tactical solutions for crop cross-breeding and diagnosing crop diseases, Khan (2008).

According to Duan (2005), most existing expert system for diagnosis was confined to medical field; and robust agricultural expert systems for practitioners are still few in number, Gal et al (2011). Also, numerous researches equally acknowledged the scarcity of works on expert systems for diagnosing and managing the pests and diseases for a certain crop (Yialouris and Sideridis, 1996; Mahaman et al, 2003; Clark et al, 1991; Koumpouros, 2004). In addition to this, most researches still focus on adoption of only one artificial technique for development of expert system for diagnosis of nutritional disorders in crops like tomato, soyabean, cassava, rice etc. A comparison study conducted on various expert systems that were not artificial intelligence-based on agriculture by Babu et al (2006), established that most classical expert systems had the capacities for fertilization scheduling, assessment of a farm and pest control, diagnosis and classification of crop diseases. Artificial intelligence is one of the most widely used concepts in computer science by researchers for modelling and simulating unambiguous tasks. Previous works have adopted various methodologies and techniques in building expert system. Diversity of methodologies mostly used in previous works include neural network, fuzzy logic, case-based reasoning, intelligent agent system, objectoriented methodology, database methodology, knowledge-based system and ontology, Shafinah et al (2013) . 
Rahmon et al., RJMCS, 2018; 2:13

Pratibha and Toran (2012) developed a neural network model to detect infected and noninfected area on soyabean plant. The symptoms are quantified and used as the dataset for training and learning. It employed back-propagation algorithm for effective learning and this made the model to be more robust in classifying and detecting the two linguistic outputs as crisps referred to as noninfected and infected areas in the model. But the proportion of these two areas could not be ascertained by the model.

The main objective of the system developed and implemented by Singh et al (2011) was to provide accessible graphic user interface for literate and its compliance by soyabeans' farmers, in order to have up-to-date knowledge on how to diagnose soyabean diseases based on symptoms. The functionality of the webbased system strongly depend on fuzzy-logic technique; having symptoms as linguistic values being converted into fuzzy-sets with the help of triangular and trapezium membership functions and adopted Center of Area (COA) as the defuzzification method for computation of weighted average of the fuzzy set. The strength of the system was responsible for its capacity to identify specific pest responsible for certain damages, and suggesting control measures for farmers. The knowledge-base of the system only consists of limited and common pest and their symptoms. The system was inefficient to tackle and diagnose pests and diseases that are not included in the rule-base.

The web-based fuzzy system proposed by Saini et al (2011) for pest management equally adopted fuzzy logic technique with more robust features to estimate pests' activity level on soyabean. It was a decision support system for farmers to acquire knowledge and information needed to manage pests and diseases attack on crops. Most researchers and software developers have discovered the potential of $\mathrm{Al}$ techniques as powerful engine in developing expert systems. The use of classical expert system in most disciplines have become obsolete due to imprecise and vagueness nature of some contemporary problems which classical expert system could not solve.

Examining the contribution of $\mathrm{Li}$ et al (2002) in the development of a web-based expert system for diagnosis of fish diseases as an intelligent system with embedded 400 rules-base and graphical user interface for users was another contribution to knowledge. It was a flexible webbased application used in diagnosing fresh water fish diseases. The system could only identify disease-type but didn't have capacity in determining the intensity rate of the disease

There is no doubt about the significant role of fuzzy logic and neural network in solving large number of problems such as prediction and classification rate in crop disease modeling in the developing world. Modeling of crop disease through the use of artificial intelligence technique based approach has been found relevant in predicting the future spread of crop disease and providing best strategies for crop infection management Qunn et al (2011).

Aderounmu et al (2013) designed a neuro-fuzzy system in which proportion of each ingredient of animal feed was determined by artificial neural network for formulation of best mixture of various ingredients for animal feeds.

In building efficient expert system, some researchers have discovered the hybridization approach as the best option in providing optimal decision support expert system for farmers. Integration of more than one artificial intelligence techniques to complement each other as adopted in this work is known as hybridization.

Gouzalez-Diaz et al (2009) investigated the need to assist farmers in developing expert system that could appropriately identify harmful organisms affecting pepper crop in Spain. The artificial intelligence technique adopted for the system development was rule-base knowledge with user interface for capturing of symptoms and embedded IF--THEN structure to infer the expert rules for possible organism affecting the 
pepper plant. Although, the reasoning and knowledge- representation of the system were highly modular, and expressed as a unit of knowledge in solving some problems. Nevertheless, the system was found to be complicated in modification of the existing knowledge base, particularly when new rules are introduced to the knowledge base which might contradict previous rules.

The proposed work of Mahaman et al (2002) equally used rule-base knowledge as a powerengine house for the expert system developed to diagnose attack of pests of honeybees on crops and provide suitable treatments. It was a Boolean logic approach method and lack capacity to provide comprehensive and specific treatment for various degrees of attack.

Pests and diseases affecting bountiful yields of tomato production were seriously tackled by integral intelligent system developed by LopezMorales (2008). The rule-base system was implemented to prevent, diagnose and control possible attack of tomato crop with pests and diseases. It was more useful for farmers who could read and access internet. But, the system was too wordy and difficult for farmers who were illiterates.

Operational Automatic Identification Tool (OAIT), supported with rule-base was designed for indigenous farmers that could not specifically identify pest attacking their crops. The main functional module of the tool was its potentiality for disease classification and suggested treatment Mahaman et al (2003).

Rice plant is more affected with paddy diseases. Researches have shown that, rice farmers were more threatened and discouraged in planting rice in some regions and areas as a result of attack of paddy diseases. The proposed model of Abdullah et al (2007) was a robust and enterprise image-based diagnosis expert system to diagnose paddy disease in rice. The expert system used fuzzy logic architecture, such as membership functions to define the degree of vagueness in appearance of lesion and colours on infected area in a rice plant for proper diagnosis. The system had better performance than other expert systems that explored rule-base knowledge technique, yet, it was a model, simulated with MATLAB for research purpose and not for end-users' advantage because of lack of friendly userinterface.

The agricultural expert system developed by Chakraborty (2008) was a fuzzy-based system that was able to provide prediction for the likely degree of occurrence malformation diseases in mangoes. Although, the system explored all the features of fuzzy logic with one type of membership function for a better performance, but in comparison with the fuzzy-based expert system proposed by Cintra et al (2011) for diagnosing tomato disease, was relatively lower in performance. The system developed by Cintra, provided various input parameters for each disease and their corresponding output. The work demonstrated Triangular membership function, Trapezoidal membership function and Gaussian membership function to define fuzzy sets for the system, with Mamdani fuzzy inference method to formulate suitable rules based upon the rule-knowledge and decision made. The output of the system was more reliable and delivered optimal solution.

Zhang et al (2010) developed an expert system with artificial neural network to diagnose various diseases that attack tomato. A large dataset was used for training and testing, and recorded high percentage of accuracy, estimated to be $95 \%$. Nevertheless, it was not a friendly user application for end-users.

The hybrid system developed by Kolhe et al (2011) was a web-based intelligent system that provided graphical user interface for end-users to diagnose diseases that affect oilseed-crops. The system was designed in an object-oriented approach, with rule-base stored in MS-SQL server database engine and fuzzy-logic was adopted for drawing inferences. The hybridization of the system comprises of fuzzylogic, object-oriented and rule-base knowledge 
technique. It was highly scalable with good The dataset that will be used for functionalities to diagnose crop diseases.

Kaloudis et al (2005) also designed an expert system that combined the rule-base knowledge and object oriented technique to diagnose forest pests that damage forest trees. The system was developed with $n$-tier architecture. An enterprise relational database management system such as MS-SQL Server was used as a base for the experts' rules while the interface was designed with ASP.NET, and C\# was used for the middle tier coding. Its benefits to users include audio-visual functionality and visual recording. But still, technically deficient in accurate computation of imprecise and vague problems.

As earlier mentioned in some literatures regarding the scarcity of robust expert system that explored the integration of variety of $\mathrm{Al}$ techniques, there is an urgent need to fill this gap by designing and developing expert systems that combine strength of various powerful techniques to form hybrid solution for indigenous soyabean-farmers in diagnosing and managing farm pests and diseases.

\section{DESIGN METHODOLOGY}

\section{DATASET DESCRIPTION} implementation will be extracted from Soybean Large Dataset (SLD), University of Califonia Institute(UCl) machine learning repository. In this study, the intention of the researcher is to collect more than one thousand (1000) records of soyabean plant disease symptoms and corresponding target output from online SLD database, and employ the assistance of agriculture experts in the domain of crop planting for proper interpretation of the dataset.

For the purpose of clarity of the dataset, each record in the dataset will be arranged with soyabean plants on rows and each column to consist of root, leaves, stem, flower and pod. These are the major components soyabean plants that can be infected with fungi, virus, pests and nematodes. When a soyabean plant is attacked with fungi, the symptom can easily be manifested on either the leaves or pod, and so on.

\section{INPUT VARIABLES}

In any dataset, the input variables are the most important parameters which are subjected to investigation by farmers into the system in order to form basis for disease diagnosis. The description of each attribute(input variable) is given below:

Table 3.1: Attributes of Datasets for Soyabean Components

\begin{tabular}{|c|c|c|}
\hline Number & Attributes & Description \\
\hline 1 & Root & The part of soyabean plant that absorbs water and nutrients \\
\hline 2 & Leaf & $\begin{array}{r}\text { The green and flat organ that represents the most prominent } \\
\text { feature of most vegetative plants. }\end{array}$ \\
\hline 3 & Stem & The above-ground stalk of a vascular plant \\
\hline 4 & Flower & $\begin{array}{r}\text { This is the colourful, conspicuous structured part of soyabean } \\
\text { plant, that is associated with angiosperms }\end{array}$ \\
\hline 5 & Pod & This is a seed case for soyabean plant. \\
\hline
\end{tabular}

Out of 35 attributes in Soyabean Large Dataset, the most relevant five (5) attributes as stated in table 3.1 will be used as input parameters for the symptoms. In the context of this work, the input parameters are referred to as linguistic variable. The linguistic values are; Very Low 
(VL), Low (L), Medium (M), High (H), Very High (VH). In a neuro-fuzzy design, the linguistic values in the dataset must be represented in form of digits for implementation as described below;

Very Low $(\mathrm{VL})=$ "1"

Low $(\mathrm{L})=$ "2"

Medium (M) = "3"

High $(\mathrm{H})=$ "4"

Very High $(\mathrm{VH})=$ " 5 "

\section{DESCRIPTION OF THE MODELING TOOL}

The proposed Neuro-Fuzzy system will be developed through MATLAB software with an ANFIS (Adaptive Neuro Fuzzy Inference System) box as shown in Fig. 3.1. The use of MATLAB guarantees result accuracy and still remain the best tool for system training and testing within short time (Maryam and Laya, 2016). The following steps are involved in modeling with ANFIS editor in MATLAB in respect to soyabean disease classification and intensity level computation.

Step 1: The collection of symptoms from various soyabean plants as input and target output in pairs will be identified and be allocated for training and testing.

Step 2: The dataset will be saved in MS-Excel file format and imported into the workspace of MATLAB by using uiimport command

Step 3: To display ANFIS editor dialogue box, anfisedit command will be typed in the MATLAB command area.

Step 4: In the ANFIS editor environment, by clicking "Load Data" command button, the data is loaded from the specified dataset for training and testing, and also to be plotted on the plot region.

Step 5: To view the structure and model of the proposed system based on the input and output, the "Generate FIS" command and structure button are clicked respectively.
Step 6: Under "Train FIS" section group, one can select FIS model parameter hybrid optimization method (a mixture of back propagation and least squares method). Also, in this section, the training epoch's number and error tolerance will be chosen.

Step 7: By clicking "Train now" button, FIS model will be trained while the membership function parameters will also be adjusted and the training data error will be plotted in the region.

Step 8: Under the "Test FIS" section group, Test button will be clicked to validate the trained FIS.

\section{ANFIS (Adaptive Neuro Fuzzy Inference System) ARCHITECTURE}

Adaptive Neuro-Fuzzy Inference System (ANFIS) is one of the hybrid neuro-fuzzy inference expert systems and it works in Takagi-Sugeno-type fuzzy inference system, which was developed by Jyh-Shing and Roger Jang (1993). The technique provides a method for the fuzzy modeling procedure to learn information about a data set, in order to compute the membership function parameters that best allow the associated fuzzy inference system to track the given input/output data. This learning method works in a manner similar to that of neural networks.

In this work, ANFIS as a hybridization of fuzzy inference system and artificial neural network is adopted as the power-engine for the proposed system. The design of appropriate membership functions to produce input-output pairs and construction of fuzzy if-then rules are carried out by ANFIS. The block diagram of ANFIS architecture is presented in Fig. 3.2 below. The ANFIS architecture uses two fuzzy if-then rules based on a first order Sugeno model. The ANFIS architecture consists of five layers of nodes performing diverse functions.

Layer-one accepts the linguistic variable symptoms (Root, Leaf, Stem, Pod and flower) as input parameters. 


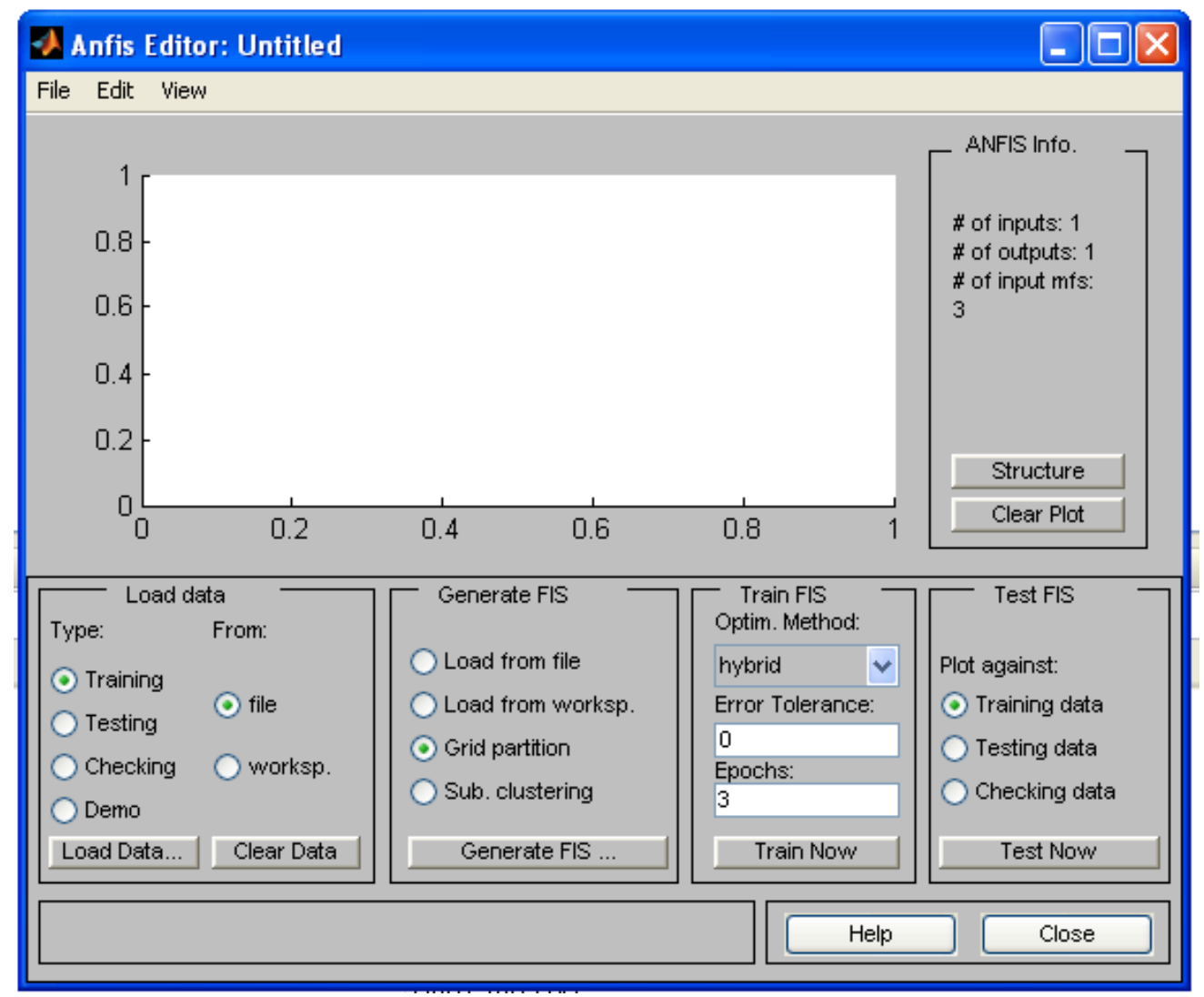

Fig. 3.1: ANFIS Editor Environment Source: Matlab,2008.

All the nodes in this layer are adaptive nodes that produce membership grade of the inputs to layer two, expressed as follow;

$\mathrm{O}^{1}{ }^{1}=\mu \mathrm{A}_{\mathrm{i}}(\mathrm{x}), \mathrm{i}=1,2$

$\mathrm{O}^{1}=\mu \mathrm{B}_{\mathrm{i}-2}(\mathrm{y}), \mathrm{i}=3,4$

Where $x$ and $y$ are the linguistic variables as input into node $i$, where $A$ is a linguistic label (Very Low, Low, Medium, High, Very high) associated with this node function is the membership function of $\mathrm{Ai}$ and it specifies the degree to which the given $x$, $y$ satisfies the quantifier $A_{i} .(x),(y)$ can adopt any fuzzy membership function. Layer-one is the fuzzification layer.

Layer-two has fixed nodes in which the incoming signals from Layer-one are multiplied and the product sent out. Each node output represents the firing strength of the rule. The output of this layer is presented as follow:

$\mathrm{O}^{2}=w_{i}=\mu \mathrm{A}_{i}(\mathrm{x}) \mu \mathrm{B}_{\mathrm{i}}(\mathrm{y}) \mathrm{i}=1$,

Layer-three also consists of fixed nodes. The ith node calculates the ratio of the ith rule's firing strength to the sum of all rule's firing strengths. Output of this layer is called normalized firing strengths.

$\mathrm{O}^{3}=\mathrm{wi}_{\mathrm{i}}=\frac{w i}{w i+w 2} \quad \mathrm{i}=1,2$

Layer-four, the nodes are adaptive nodes like Layer-one. In this layer, the product of the normalized firing strength, with the first order polynomial, is the output of each node in layer four.

$\mathrm{O}^{4}=\mathrm{w}_{\mathrm{i}} \mathrm{f}_{\mathrm{i}}=\mathrm{wi}_{\mathrm{i}}\left(\mathrm{p}_{\mathrm{i}} \mathrm{x}+\mathrm{q}_{\mathrm{i}} \mathrm{y}+\mathrm{r}_{\mathrm{i}}\right) \mathrm{i}=1,2----$

Layer-five is the last fixed node which produces the output by summing all incoming signals as presented below.

$\mathrm{O}_{\mathrm{i}}^{5}=\sum \mathrm{W}_{\mathrm{i}} \mathrm{f}_{\mathrm{i}}=\frac{\sum i w i f i}{\sum i w i} \quad \mathrm{i}=1,2$

\section{PROPOSED NEURO-FUZZY SYSTEM}

The diagram in Fig 3.3 below consists of five stages: input stage, fuzzification, rule base, inference engine, and defuzzification. The first stage allows the crisp inputs such as manifested symptoms on root, leaf, stem, flower, and pod to be passed into the fuzzification stage of second step in order to be converted into fuzzy inputs with the help of 
gaussian membership function. From the training the inference engine with back fuzzifier, the membership functions of the fuzzy propagation algorithm is for the proper rules to input are fed into the neural network block be generated which would be fired from neural which consists of inference engine connected network to produce linguistic output. The to the rule-base. Back propagation algorithm defuzzifier then converts the linguistic output will be used to effectively train the inference generated by neural network to crisp output i.e. engine for the appropriate selection of rule the severity level of a particular soyabean base. It should be noted that; the purpose of disease in floating number.

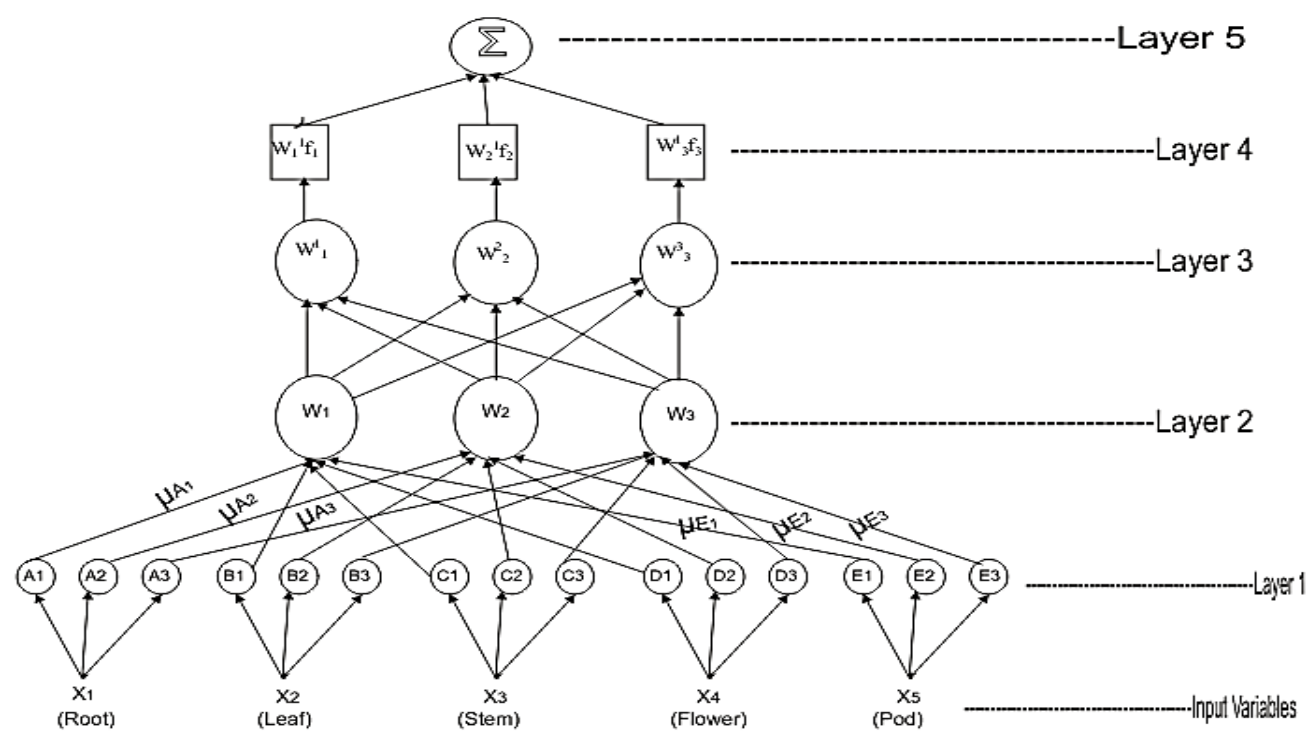

Fig. 3.2: Block Diagram of ANFIS Architecture Source: Journal of Theoretical and Applied Information Technology

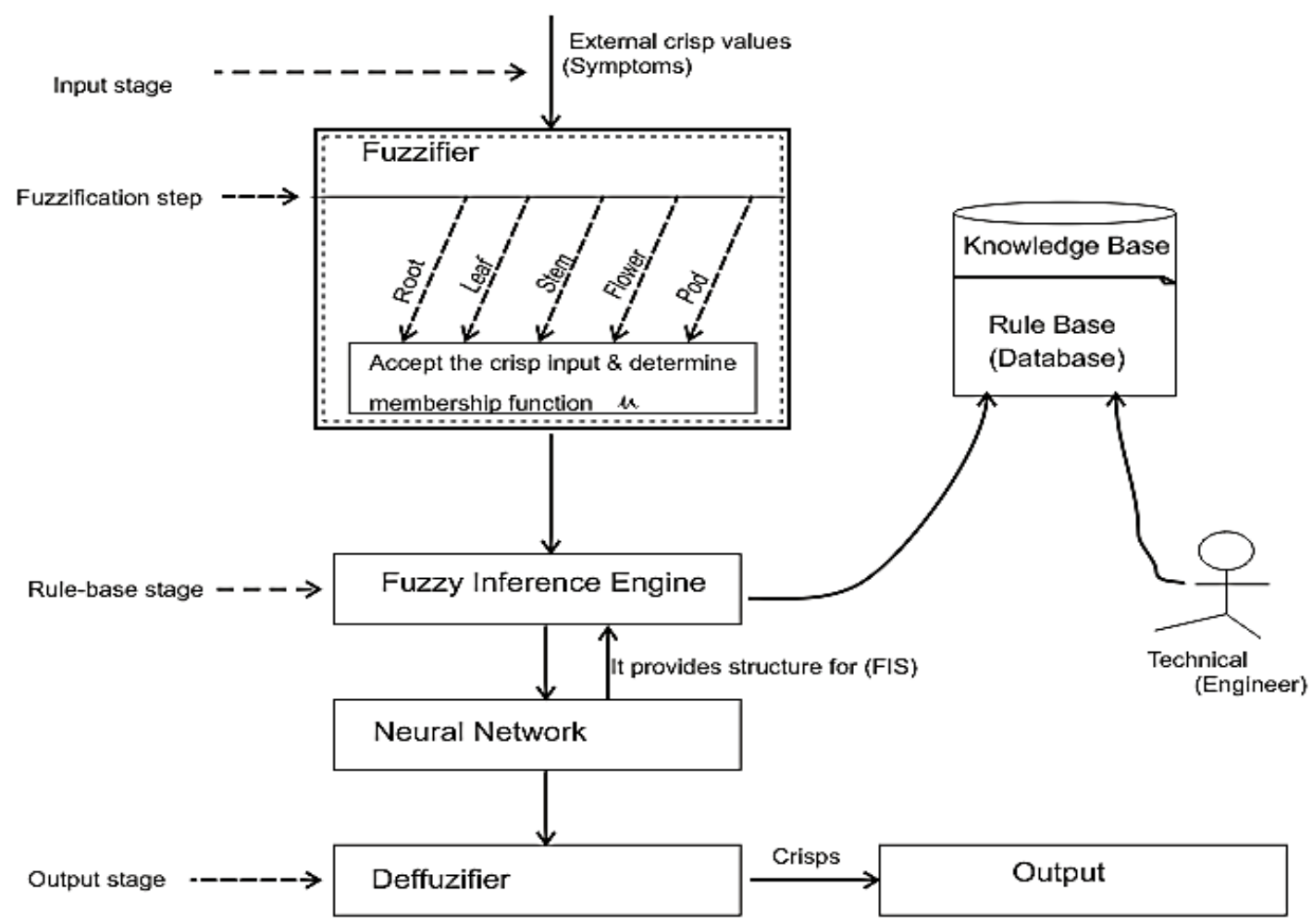

Fig. 3.3: Conceptual Diagram of Neuro-Fuzzy Model for Soyabean Disease Diagnosis ( Proposed Model).

http://escipub.com/research-journal-of-mathematics-and-computer-science/ 


\section{System Validation}

It is a process of presenting untrained input/output dataset to the trained Fuzzy Inference System (FIS) in order to ascertain the extent to which the FIS model would determine the intensity level corresponding to the set output values. The proposed neuro fuzzy system will be validated through the testing data supplied to it after it has been trained. Mean Square Error (MSE) will be used as an evaluating formular to check the accuracy performance of the model by measuring the differences between original data and obtaining values. MSE formular is given below:

$M S E=\frac{1}{n} \sum_{i=1}^{n}\left(a_{(i)}-b_{(i)}\right)^{2}$

$\mathrm{n}$ is the number of pair-data in the dataset $\mathrm{a}_{(\mathrm{i})}$ are the set of ith desired output $b_{(i)}$ are the set of ith target output

\section{Defuzzification}

This technique involves computation of sampled membership functions in order to establish their membership grade to be used in fuzzy logic expression and thereby determine outcome region or produce a single scalar quantity. Out of the two methods of defuzzification which include; Mean of Maximum (MOM) and Center of Area or Centroid (COA), COA is the most popular and appealing of all the defuzzification methods (Sugeno, 1985; Lee, 1990). For this reason, COA method will be adopted to calculate the weighted average of the fuzzy set in the system by using the algebraic expression below;

$\frac{\int_{z} \mu A(z) \cdot z d z}{\int_{z} \mu A(z) \cdot z d z}$

Where $z$ is the output variable $(z)$ is the membership function of the aggregated fuzzy set $A$ with respect to $z$

\section{Fuzzy Rule Base}

Fuzzy implication rules will be adopted to mimic expert's reasoning with statements that are imprecise by nature. With the assistance of Agriculture experts, more than one thousand rules will be generated based on diverse symptoms affecting root, stem, leaf, pod and flower of a soyabean's plant in accordance with the knowledge on the disease domain. The fuzzy rules are strictly linguistic rules of IF ---THEN format.

Table 3.2: Collection of rule-base for Soyabean diseases

\begin{tabular}{|c|c|c|c|c|c|c|c|}
\hline S/N & $\begin{array}{c}\text { Root } \\
\text { Feeds on } \\
\text { the root }\end{array}$ & $\begin{array}{c}\text { Leaves } \\
\text { Perforated } \\
\text { and turn } \\
\text { yellow }\end{array}$ & $\begin{array}{c}\text { Stem } \\
\text { Hollow stem } \\
\text { and zigzag } \\
\text { tunnel on } \\
\text { stem }\end{array}$ & $\begin{array}{c}\text { Pods } \\
\text { Eats pod }\end{array}$ & $\begin{array}{c}\text { Flower } \\
\text { Feeds on } \\
\text { flowers }\end{array}$ & $\begin{array}{c}\text { Linguistic } \\
\text { value } \\
\text { Output1 }\end{array}$ & $\begin{array}{c}\text { Severity } \\
\text { Level } \\
\text { Output2(\%) }\end{array}$ \\
\hline 1 & $\mathrm{H}$ & $\mathrm{H}$ & $\mathrm{M}$ & $\mathrm{H}$ & $\mathrm{L}$ & $\mathrm{VH}$ & $85 \%$ \\
\hline 2 & $\mathrm{M}$ & $\mathrm{L}$ & $\mathrm{M}$ & $\mathrm{H}$ & $\mathrm{VL}$ & $\mathrm{M}$ & $52 \%$ \\
\hline 3 & $\mathrm{VL}$ & $\mathrm{L}$ & $\mathrm{VL}$ & $\mathrm{M}$ & $\mathrm{H}$ & $\mathrm{L}$ & $28 \%$ \\
\hline$\cdot$ & & & & & & & \\
\hline. & & & & & & & \\
\hline. & & & & & & & \\
\hline 1000 & $\mathrm{~L}$ & $\mathrm{~L}$ & $\mathrm{M}$ & $\mathrm{L}$ & $\mathrm{L}$ & $\mathrm{L}$ & $20 \%$ \\
\hline
\end{tabular}

\section{IF A THEN B}

Where $A$ is referred to as the premise and $B$ depicts the consequence of the rule.
In the rule bank, there will be one thousand rules. Each rule is a collection of fuzzy sets (Very Low, Low, Moderate, High, and Very High) from a list of symptoms that have 
occurred, combined together with "AND" in order to show the definite status of a specific soyabean disease. The rules are shown in Table 3.1 where $(\mathrm{VL}=$ Very Low, $\mathrm{L}=$ Low, $\mathrm{M}=$ Medium, High $=\mathrm{H}$, and VH = Very High)

From Table 3.2, rule 1 could be defined as follow;

Rule 1: If $($ Root $=H$ \& Leaves $=H$ \& Stem $=M$ \& Pods $=\mathrm{H} \&$ Flower $=\mathrm{L}$ ) then Output1 $=$ VH, Output2 = 85\%

\section{SUMMARY AND CONCLUSION}

The proposed system will provide optimal benefits over the shortcomings found in works that were reviewed, because, once the system has been set-up, neuro-fuzzy technique embedded within the system, has the capacity to identify which of the rules have been developed by the system in order to be examined by experts to ensure that the problems are appropriately addressed. This system will be more effective and efficient to use in the diagnosis of soyabean diseases and determining the intensity level of the disease by using ANFIS. The output will show the intensity and classification of any disease as very low, low, medium, high and very high. The design of the system can be divided into 3 stages: ANFIS model development, network training and system validation and testing. When this system is implemented, it will be found that neuro-fuzzy based system will be more suitable and feasible to be used as a supportive tool for soyabeans disease diagnosis.

\section{References}

1. Abdullah, S., Bakar, A.A., Mustafa, N., Yusuf, M., and Hamdan, A.R. (2007). Fuzzy Knowledge Modelling for Image-based Paddy Disease Diagnosis Expert System: Proceedings of the International Conference on Electrical Engineering and Informatics, Institute TeknologiBandung (Indonesia), June 17-19, pp. 642-644.

2. Aderounmu, G.A., Omidiora E.O., Adegoke, B.O., and Taiwo T.A., (2013). Neuro-fuzzy System for Livestock Feed Formulation (Africa Poultry): International Journal of Engineering and Science (IJES), 2(5), pp.25 - 32.
3. Asoegwu, S.N, Asoegwu A.O. (2007). An overview of Agricultural Mechanization and Its Environmental Management in Nigeria: Agricultural Engineering International: The

4. CIGR Ejournal; 9(6): pp.6-18.

5. Babu, M.S., and Roa, N.T. (2010). Implementation of Artificial Bee Colony (ABC) Algorithm On Garlic Expert Advisory System: International Journal of Computer Science and Research, Vol. 1, No. 1, pp. 69-74.

6. Cintra, M.E., Meira, C.A., Monard, M.C., Camargo, H.A. and Rodrigues, L.H. (2011): The use of fuzzy decision trees for coffee rust warning in Brazilian crops: 11th International Conference on Intelligent Systems Design and Applications (ISDA), November 22-24, pp. 13471352.

7. Duan, J.S., Edwards, and Xu, M.X. (2005): WebBased Expert Systems: Benefits and Challenges", Information and Management, Vol. 42, No. 6, pp. 799-811.

8. Dugje, I.Y., Omoigui, L.O., Ekeleme, F.,Bandyopadhyay, R., Lava-Kuma P, and Kamara, A.Y. (2009): Farmers' Guide to Soybean Production in Northern Nigeria. IITA, Ibadan, Nigeria

9. Le Gal, P.Y., Dugué, P., Faure, G. and Novak, S. (2011): How Does Research Address The Design of Innovative Agricultural Production Systems At The Farm Level? A review, Agriculture Systems Vol. 104 No. 9, pp. 714-728.

10. Gonzalez-Diaz, L. , Martínez-Jimenez, P., Bastida, F., and Gonzalez-Andujar, J.L. (2009): Expert System For Integrated Plant Protection In Pepper (Capsicum annuun L.), Expert Systems With Applications, Vol. 36, No. 5, pp. 8975-8979.

11. Kaloudis, S., Anastopoulos, D., Yialouris, C.P. Lorentzos, N.A. and Sideridis, A.B.(2005): Insect Identification Expert System For Forest Protection, Expert Systems with Applications, Vol. 28, No. 3, pp. 445-452.

12. Khan, S. F., Razzaq, S., Irfan, K., Maqbool, F., Farid A., Illahi, I. and Tauqeerulamin, (2008): A Web-based Expert System for Diagnosis of Diseases and Pests in Pakistani Wheat, Proceedings of the World Congress on Engineering, London, UK,(1):pp. 1-6,.

13. Kolhe, S., Kamal, R., Saini, H.S. and Gupta, G.K., (2011): A Web-Based Intelligent DiseaseDiagnosis System Using A New Fuzzy-Logic Based Approach For Drawing The Inferences In Crops", Computers and Electronics in Agriculture, Vol. 76, No. 1, pp. 16-27.

14. Koumpouros, Y., Mahaman, B.D., Maliappis, M., Passam, H.C., Sideridis, A.B. and Zorkadis, V. (2004): Image Processing For Distance 
Diagnosis In Pest Management", Computers and Electronics in Agriculture, Vol. 44, No. 2, pp. 121131.

15. Li, D., Fu, Z. and Duan, Y. (2002): Fish-Expert: A Web-Based Expert System For Fish Disease Diagnosis, Expert Systems with Applications, Vol. 23, No. 3, pp. 311-320.

16. López-Morales, V., López-Ortega, O., RamosFernández, J., and Muñoz (2008): JAPIEST: An Integral Intelligent System For The Diagnosis And Control Of Tomatoes Diseases And Pests In Hydroponic Greenhouses, Expert Systems with Applications, Vol. 35, No. 4, pp. 1506-1512.

17. Mahaman, B.D., Passam, H.C., Sideridis, A.B., and Yialouris, C.P. (2003): DIARES-IPM: A Diagnostic Advisory Rule-Based Expert System For Integrated Pest Management In Solanaceous Crop Systems, Agricultural Systems, Vol. 76, No. 3, pp. 1119-1135.

18. Patterson, D.W. (2004): Introduction to Artificial Intelligence and Expert Systems. Prentice-Hall: New Delhi.

19. Quinn, J. A., Leyton-Brown, K., Mwebaze, E. (2011): Modeling and Monitoring Crop Disease in Developing Countries. Conference of the Association for the Advancement of Artificial

20. Intelligence (AAAI), .

21. Shafinah K.,Noraidah,S., Riza, S., Mohd S., Mohammad, M. (2013): A Framework Of An Expert System For Crop Pest And Disease Management: Journal of Theoretical and Applied Information Technology, 10th December, Vol. 58 No. 1

22. Saini, G.K., Gupta, S., Kolhe, R. Kamal, H.S. (2011): A Web-Based Intelligent DiseaseDiagnosis System Using A New Fuzzy-Logic Based Approach For Drawing The Inferences In Crops, Computers and Electronics in Agriculture, Vol. 76, No. 1, pp. 16-27.

23. Singh, A., Singh,S.K., Sarma, K.R. (2010): An Expert System For Diagnosis Of Diseases In Rice Plant, International Journal of Artificial Intelligence, Vol. 1, No. 1, pp. 26-31.

24. Yialouris, C.P. and Sideridis, A.B. (2010): An Expert System For Tomato Diseases, Computers And Electronics In Agriculture, Vol. 14, No. 1, pp. 61-76.

25. Zhang, K., Chai, Y. and Yang, S.X. (2010): SelfOrganizing Feature Map For Cluster Analysis In Multi-Disease Diagnosis, Expert Systems With Applications, Vol. 37, No. 9, pp. 6359-6367. 